\title{
Oestrogen replacement therapy after hysterectomy
}

\author{
Tony Seeley
}

\begin{abstract}
Objective-To identify those women who might benefit from oestrogen replacement after hysterectomy.

Design-Targeted health screening.

Setting-Large group practice.

Subjects-All women aged under 50 who had had a hysterectomy.

Main outcome measures-Concentration of follicle stimulating hormone, symptom profile, uptake of oestrogen replacement therapy.

Results -145 of 1953 women aged 32-49 had had a hysterectomy. 35 of the 41 with bilateral oophorectomy and 27 of 104 with one or more ovaries conserved were taking oestrogen replacement. 62 of the 68 who had ovaries conserved and were not taking oestrogen replacement attended for review, of whom 14 had a follicle stimulating hormone concentration $\geqslant 20$ IU/1. 16 of the 19 women identified as potentially able to benefit from oestrogen replacement started treatment and were still on treatment at six months of follow up.

Conclusion-Systematic review of women who had had a hysterectomy identified an important group who would potentially benefit from oestrogen replacement therapy.
\end{abstract}

\section{Introduction}

Oestrogen replacement can benefit menopausal women by reducing the incidence of ischaemic heart disease, stroke, and osteoporosis. ${ }^{1}$ This treatment can confer benefits after hysterectomy. Although the ovaries are usually conserved when a hysterectomy is performed in women under the age of 45 , the operation may advance ovarian failure by about four years. ${ }^{2}$ In older women the ovaries are usually removed and oestrogen replacement given.

It was suspected that a significant proportion of younger women who had had a hysterectomy and might benefit from oestrogen replacement therapy were not receiving it. I conducted a study to identify these women and offer them treatment.

\section{Subjects and methods}

Bridgnorth medical practice serves 15000 patients in a small country town. The ovarian status and use of oestrogen replacement by women aged under 50 who had had a hysterectomy were obtained from patients' records.

Women who had had their ovaries removed were

Northgate House, Bridgnorth, Shropshire WV16 4BU

Tony Seeley, general practitioner

BMf 1992;305:811-2 invited to discuss oestrogen replacement with their doctor unless there were absolute contraindications (breast or endometrial carcinoma, severe active liver disease, undiagnosed vaginal bleeding).

Women who had had a hysterectomy with ovarian conservation and were not taking oestrogen replacement were invited for an assessment of menopausal symptoms by a practice nurse an arbitrary minimum of one year after their operation. Menopausal symptoms were rated as present or absent on a precoded sheet. Concentration of follicle stimulating hormone was measured as an index of ovarian failure (polyclonal radioimmune assay, postmenopausal reference range $\geqslant 30 \mathrm{IU} / \mathrm{l})$. Patients were asked to consult their doctor if symptoms were troublesome or their follicle stimulating hormone concentration was $20 \mathrm{IU} / \mathrm{l}$ or above. $^{3}$

\section{Results}

Of 1953 women aged 32 to 49,145 had had a hysterectomy. Forty one had also had bilateral oophorectomy. The mean age of these 41 women was 44 (range 33-49) years, and the mean age at operation was $41(28-48)$ years. Thirty five of the 41 women were taking oestrogen replacement, with a median duration of treatment of three years (range $<1-13$ ). Of the six women not taking oestrogen replacement, two had no evidence of malignancy, two ovarian carcinoma, one endometrial sarcoma, and one had no evidence of malignancy but subsequently developed chronic active hepatitis. All but the last woman were judged to be suitable for oestrogen replacement.' Three women started treatment. One woman with ovarian carcinoma declined treatment after other medical advice and the fifth woman did not accept an invitation to attend.

In all, 104 women had had a hysterectomy with conservation of ovaries; 27 were already taking oestrogen replacement therapy. Of the 77 who were not taking oestrogen, nine had had a hysterectomy in the past year. The remaining 68 were invited for an assessment and $62(91 \%)$ attended (table). Fourteen women had a raised follicle stimulating hormone concentration, 13 of whom started oestrogen replacement. One woman declined treatment. Menopausal type symptoms were common but only hot flushes were reported significantly more often by the women with a raised follicle stimulating hormone concentration $\left(57 \% v 25 \%, \chi^{2}=3 \cdot 7, \mathrm{df}=1 ; \mathrm{p}=0.05\right)$. Of the 19 women who were identified as potentially able to benefit from oestrogen replacement, 16 started treatment and all were still taking it six months later.

\section{Discussion}

Oestrogen deficiency has particularly severe consequences in younger women and this study concentrated on women under 50.' The quoted follicle stimulating hormone postmenopausal reference range of $\geqslant 30$ IU is comfortably over any spontaneous midcycle ovulatory peak and a concentration of $20 \mathrm{IU} / \mathrm{t}$ was selected to indicate ovarian failure. ${ }^{3}$

Oestrogen replacement therapy was already being taken by $85 \%$ of women who had had oophorectomy, a much higher rate than reported in previous studies. ${ }^{49}$ 
Characteristics of women who had had hysterectomy with ovarian conservation not taking oestrogen replacement therapy according to follicle stimulating hormone concentration

\begin{tabular}{lccc}
\hline & \multicolumn{2}{c}{ Follicle stimulating hormone } & \\
\cline { 2 - 3 } & $<20$ IU $/ 1$ & \multirow{2}{*}{$\geqslant 20$ IU/l } & p Value \\
\hline No of women & 48 & 14 & \\
Mean (range) age (years) & $44(34-49)$ & $46(41-49)$ & NS \\
Mean (range) age at operation (years) & $39(30-47)$ & $41(38-45)$ & NS \\
Mean (range) follicle stimulating hormone (IU/l) & $6(1-19)$ & $38(20->50)^{\star}$ & \\
No (\%) with hot flushes & $12(25)$ & $8(57)$ & 0.05 \\
No (\%) with vaginal dryness & $19(40)$ & $4(29)$ & NS \\
No $(\%)$ with psychological symptoms & $34(71)$ & $12(86)$ & NS \\
No (\%) with reduced libido & $18(38)$ & $6(43)$ & NS \\
\hline
\end{tabular}

${ }^{\star}$ Maximum concentration reported by laboratory as $>50$ in three women.

This may reflect the enthusiasm of the practice staff but could indicate changing prescribing patterns within general practice.

Women who have had a hysterectomy are ideal patients for oestrogen replacement therapy. Un- opposed oestrogen is the treatment of choice and the British National Formulary recommends 10 years' use. These women do not have periods or premenstrualtype symptoms and receive the full benefit of the oestrogen mediated lipid improvements.

I thank our practice nurses, Sarah Hammerton for clerical help, and Dr Peter Allman, Dr Jean Coope, Mr Alan Smith, and $\mathrm{Mr}$ David Sturdee for their comments on the manuscript.

1 Whitehead M, Godfree V. Hormone replacement therapy. Your questions answered. Edinburgh: Churchill Livingstone, 1992.

2 Siddle N, Sarrel P, Whitehead M. The effect of hysterectomy on the age at ovarian failure. Fertil Steril 1987;47:94-100.

3 Tindall VR. Yeffcoate's principles of gynaecology. London: Butterworths, 1987.

4 Spector TD. Use of oestrogen replacement therapy in high risk groups in the United Kingdom. BMF 1989;299:1434-5.

5 Barlow DH, Grosset KA, Hart H, Hart DM. A study of the experience of Glasgow women in the climacteric years. Br $\mathcal{f}$ Obstet Gynaecol 1989;96: 1192-7.

(Accepted 8 September 1992)

\section{ANY QUESTIONS}

What is the cause of the headache that occasionally occurs as a side effect of treatment with ranitidine?

Ranitidine is an $\mathrm{H}_{2}$ receptor blocker used in peptic ulcer, and, although headache is recorded as an adverse reaction, it seems to be uncommon. Histamine has been implicated in cluster headache, but this is not documented as a side effect of $\mathrm{H}_{2}$ blockers. The mechanism of headache is obscure since only $\mathrm{H}_{2}$ receptors are present on intracranial vessels, but both $\mathrm{H}_{1}$ (vasoconstrictor) and $\mathrm{H}_{2}$ (vasodilator) receptors are found on extracranial arteries. The usual effect of physiological doses of histamine is pronounced vasodilatation mediated by $\mathrm{H}_{1}$ and $\mathrm{H}_{2}$ receptors, which is accompanied by a throbbing diffuse headache and flushing, quite distinct from migraine.' This might be inhibited by an $\mathrm{H}_{2}$ blocker. Experimentally intracarotid histamine does not alter cerebral blood flow when the blood-brain barrier is intact. Whether ranitidine causes a relative excess of $\mathrm{H}_{1}$ activity followed by a rebound of $\mathrm{H}_{2}$ activity is a guess that might explain the occasional headaches after its use. A non-specific headache of tension type might be another explanation in sufferers from peptic ulcer.-J M S PEARCE, consultant neurologist, Hull

1 Gross PM, Harper AM, Teasdale GM. Cerebral circulation and histamine. 1. Participation of $\mathrm{H}_{1}$ - and $\mathrm{H}_{2}$-receptors in vasodilatory responses to 1. Participation of $\mathrm{H}_{1}-$ and $\mathrm{H}_{2}$-receptors in vasodilatory respon
intracarotid infusion. 9 Cereb Blood Flow Metab 1981;1:97-108.

Can non-steroidal anti-inflammatory drugs given before operations affect wound healing? If so, is their effect important enough for doctors to recommend prohibition of their use during this period?

The implications of an affirmative reply are obvious, aside from the known side effects of non-steroidal anti-inflammatory drugs, which could be a particular problem during and after surgery-increased bleeding of the wound bed, confusion, and postoperative gastric haemorrhage. ${ }^{1}$ The specific question is whether non-steroidal anti-inflammatory drugs adversely affect wound healing. I infer that the questioner is concerned with surgery other than that directly on the intestinal tract and, in particular, whether non-steroidal anti-inflammatory drugs adversely impair healing after orthopaedic surgery. There is anecdotal evidence for impairment ${ }^{2}$ and experimental evidence ${ }^{3}$ against impairment, but controlled comparisons directly addressing this issue are lacking. To withdraw symptomatic relief in the form of non-steroidal anti-inflammatory drugs from patients with, for example, actively painful osteoarthritis during the postoperative phase may greatly impair the patients' postoperative rehabilitation and therefore their recovery from surgery. That could be a more decisive disadvantage than a minor delay in healing, should this in fact occur.

In the absence of strong evidence for or against the use of anti-inflammatory drugs before operation I recommend, firstly, that adequate pain relief with analgesics should be assured without the use of nonsteroidal anti-inflammatory drugs except when these are definitely indicated, such as in postoperative gout. Secondly, when there seems to be a good clinical indication for non-steroidal anti-inflammatory drugs before an operation a drug with a short half life should be used.-MICHAEL L SNAITH, senior lecturer in rheumatology, Sheffield

1 Connelly CS, Panush RS. Should nonsteroidal anti-inflammatory drugs be stopped before elective surgery? Arch Intern Med 1991;151:1963-6.

2 Proper SA, Fenske NA, Burnett SM, Luria LW. Compromised wound repair caused by perioperative use of ibuprofen. I Am Acad Dernatol 1988;18:1173-9.

3 Mbugua SW, Skoglund LA, Likken P. Effects of phenylbutazone and indomethacin on the post operative course following experimental orthopaedic surgery in dogs. Acta Vet Scand 1989;30:27-35.

Are there appreciable amounts of nitrosamines in smoked fish such as kippers (which are cold smoked), smoked mackerel, and salmon (hot smoked), and if so what amount can be safely consumed each week without long term risk.

Nitrosamines, notably $N$-nitrosodimethylamine, have been found in measurable amounts in several samples of both raw and processed fish.' The levels observed have been up to $10 \mathrm{mg} / \mathrm{kg}$, average being about $0.3 \mathrm{mg} / \mathrm{kg}$. Smoking using gas heating produced a substantial increase in the levels in kippers but electric heating did not. ${ }^{2}$

Artificial smokes applied as a solution do not contain nitrosamines. The effects of traditional wood smoking vary depending on temperature and the type of wood used, which affects the formation of nitrous oxide. In view of the highly variable concentrations it is impossible to state the upper level of fish consumption that would carry no long term risk, but at the levels reported fish would make a minor contribution to total intakes which are well below the provisional acceptable daily intakes. Epidemiological studies show that the consumption of smoked fish is not significantly associated with the incidence of gastric cancer. ${ }^{3}$ - D A T SOUTHGATE, head of nutrition, diet, and health department, Institute of Food Research, Norwich

1 Ministry of Agriculture, Fisheries and Food. Nitrate, nitrite and $\mathrm{N}$-nitroso compounds in food. Second report of the steering group on food surveillance. London: HMSO, 1987. (Food surveillance report No 20.)

2 Ministry of Agriculture, Fisheries and Food. Nitrate, nitrite and $\mathrm{N}$-nitroso compounds in food. Second report of the steering group on chemical aspects of food surveillance. London: HMSO, 1992. (Food surveillance report No 32.)

3 Choi NW, Miller AB, Fodor JG, et al. Consumption of precursors of $\mathrm{N}$-nitroso compounds and human gastric cancer. In: Bartsch $\mathrm{H}, \mathrm{O}$ 'Neill $\mathrm{IK}$, Schutte-Herm R, eds. Relevance of $\mathrm{N}$-nitroso compounds to human cancer: exposure and mechanisms. Lyon: International Agency for cancer: exposure and mechanisms. Lyon: Internation 